\title{
The learning of patterned strings problems by rock squirrels'
}

JAMES E. KING AND EDWIN D. WITT UNIVERSITY OF ARIZONA
A sequence of patterned strings problems was presented to four rock squirrels in a scaled down WGTA. All Ss learned a series of parallel patterns; however, only one $S$ was able to learn the entire sequence including crossed and pseudocrossed pattems. The later performance of this $S$ on an intermixed series of crosses and pseudocrosses indicated that it could not perform efficiently on both problems simultaneously.

Patterned strings problems are typically defined by presenting $S$ with various configurations of two or more strings, one of which has a conspicuous reward attached at one end. The $\mathrm{S}$ learns to select the string with the attached reward and in so doing must utilize the position of the reward relative to the pattern formed by the strings.

Past investigations of patterned strings learning have been conducted most exclusively with primates including rhesus monkeys (Harlow \& Settlage, 1934), champanzees (Finch, 1941) and lowland gorillas (Riesen et al, 1953). Some work on string pulling by dogs and cats has been reported (Richardson, 1932; Trueblood \& Smith, 1934) but this research was, more often than not, informal and anecdotal and did not conclusively demonstrate discrimination of different string patterns by these carnivores. However, more recently, Michels et al (1961) showed that raccoons can become proficient at solving moderately complex string patterns if a sufficient number of trials are presented.

The study of patterned strings performance in the rock squirrel was undertaken in order to determine the extent to which a member of the rodent order can evidence learning on this task. Among the rodent species, squirrels would appear to be particularly well suited for patterned strings testing because of their highly developed visual and manipulatory abilities. Method

The Ss were three female (F1, F2, and F3) and one male (M1) adult rock squirrels. All of these Ss had been raised in captivity and had extensive previous experience on discrimination and reversal learning-setproblems (King, 1965).

Testing was conducted in a scaled down version of the WGTA. The strings were constructed from $1 / 8 \mathrm{in}$. silver beaded chain with swivel hooks at each end. The strings were attached to the front edge of a 14 in. by $9-3 / 4$ in. black sliding tray which was tilted toward the test cage at a $5^{\circ}$ angle. The food cup was a 1-1/4 in. diameter cylindrical section of aluminum weighing $52 \mathrm{gm}$ which had a small depression on the top into which bits of raisins were inserted as rewards.
The Ss were initially trained to pull in a single baited string centered on the tray. All Ss learned to perform the chain pulling efficiently within three or four $1 / 2-\mathrm{hr}$. test sessions by using both their front paws and their teeth. The Ss were then tested for 25 trials per day on the sequence of patterns which are shown in Table 1. This sequence began with a series of parallel patterns of increasing difficulty (1 through 4 ) and ended with crossed and pseudocrossed patterns (9 and 10). There was a $1 / 2$ in. gap between the two strings at their closest point in the pseudocross. The two asymmetrical patterns (5 and 8 ) were placed in mirror image reversals every five trials.

The Ss were tested on each pattern until they attained a criterion of 20 out of 25 correct trials, all within a single test session. If an $\mathrm{S}$ failed to meet this criterion within 2500 trials, testing of that $S$ was discontinued. In order to prevent the establishment of strong position habits, whenever an $S$ responded to one side on 10 successive trials, the opposite side was consistently rewarded until a response to that side occurred. If an $S$ learned all 10 patterns, it was then presented with 250 trials of an intermixed series of crosses and pseudocrosses with the sequence of patterns derived from a Gellerman series.

Results

Table 1 depicts the total number of errors committed by each $\mathrm{S}$ on each problem that was learned. These data show that the Ss were quite slow in learning the initial parallel pattern ( 4 in. strings) and that there were marked individual differences, the number of errors to criterion varying from 27 to 1036 . The subsequent parallel patterns (Nos, 2, 3, and 4) were learned with more facility than the initial parallel pattern but the transfer was far from complete.

Following introduction of the nonparallel patterns, F2 failed to reach criterion on the slanted pattern (No. 5) while F3 and M4 failed to reach criterion on the diverging (No. 6) and the converging (No. 7)

$$
\begin{aligned}
& \text { PATTERN (Scole: } k \rightarrow=5 \text { in) }
\end{aligned}
$$

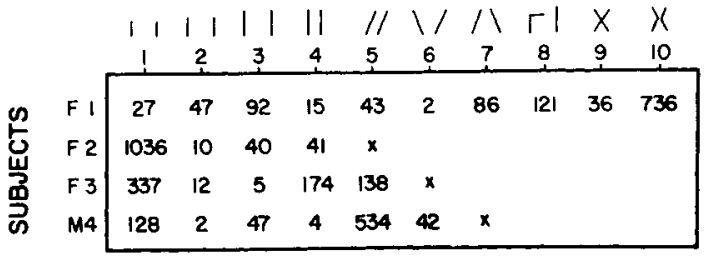

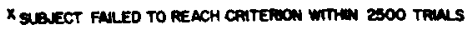

Table 1. Errors to criterion for each pattern. 
patterns respectively. Only F1 completed the entire series of problems, learning both the crossed and the pseudocrossed patterns. After this Slearned the crossed pattern with 36 errors, it committed 736 errors during the learning of the pseudocrossed patterns, a result which suggested negative transfer from the former to the latter pattern.

During the first half of the intermixed series of crosses and pseudocrosses, F1 made $67 \%$ correct responses on the pseudocrosses and $47 \%$ correct responses on the crosses ( $p<.04$ with 2 -tailed binomial test). There was no significant difference between performances on the two patterns during the second half of the intermixed series.

\section{Discussion}

This experiment has shown that, given sufficient practice, rock squirrels are capable of learning simple patterned string problems. This outcome demonstrates that patterned strings learning is possible in rodents as well as in carnivores and primates. However, even the 4 in. parallel pattern was clearly a formidable problem for the squirrels. Only one of the four squirrels tested was able to complete the entire sequence of the problems and the performance of that squirrel on the intermixed series of crossed and pseudocrossed patterns gave no evidence that it was able to perform above chance level on both patterns simultaneously. In contrast, Michels et al (1961) showed that racoons, after learning crossed and pseudocrossed patterns separately, were able to perform efficiently on an intermixed series.

The low performance of the squirrel that was tested on the intermixed series suggests that it was not learning to follow the paths of the chains during the preceding problems but was instead learning a spatial discrimination conditional upon the location of the food cup. Relatively small gaps between the locus of response and the discriminative stimulus typically result in markedly lowered performance in the WGTA (see Stollintz, 1965). If patterned strings learning by rock squirrels is regarded as a simple discrimination problem, then the slowness of this species to learn simple parallel patterns is consistent with the importance of stimulus-response contiguity in discrimination learning.

\section{References}

Finch, G. The solution of patterned strings probiems by chimpanzees. J. comp. Psychol., 1941, 32, 83-90.

Harlow, H. F. \& Settlage, P. H. Comparative behavior of primates: VII. Capacity of monkeys to solve patterned strings tests. $J$. comp. Psychol., 1934, 18, 423-435.

King, J. E. Discrimination and reversal learning in the rock squirrel. Percept. mot. Skills, 1965, 20, 271-276.

Miche Is, K. M., Pustek, J. J. Jr., \& Johnson, J. 1. Jr. The solution of patterned strings problems by raccoons. J. comp. physiol. Psychol., 1961, 54, 439-441.

Richardson, H. M. The growth of adaptive behavior in infants. Genet. Psychol. Monogr., 1932, 12, 195-357.

Riesen, A. H., Greenberg, B., Granston, A. H., \& Fantz, R. L. Solutions of patterned strings problems by young gorillas. $J$. comp. physiol. Psychol., 1953, 46, 19-22.

Stollnitz, F. Spatial variables, observing responses, and discrimination learning sets. Psychol. Rev., 1965, 72, 247-261.

Trueblood, C. K.. \& Smith, K. U. String pulling behavior of the cat. J. genet. Psychol., 1934, 44, 413-427.

Note

1. This research was supported by Public Health Service Research Grant MH-12046 from the National Institute of Mental Health. 